\title{
EMG patterns in abnormal involuntary movements induced by neuroleptics
}

\author{
N BATHIEN, RM KOUTLIDIS, P RONDOT
}

From the Service de Neurologie, Hôpital Saint-Anne, Cochin-Port-Royal, and the Laboratoire de Physiologie, Faculté de Médicine, Saint-Antoine, Paris France

SUMMARY Electromyographic (EMG) activity of abnormal involuntary movements and their modifications after Piribedil, a dopaminergic agonist, were analysed in patients presenting with tremor or tardive dyskinesia induced by treatment with neuroleptics. Quantitative analysis of EMG bursts and of their phase relationships with bursts of antagonist muscles revealed differences between tremor and tardive dyskinesia; three separate EMG types of the latter were found. In tremor, EMG activity was coordinated between agonists and antagonists. Length and frequency of bursts are characteristic. In tardive dyskinesia, phase histograms of antagonist muscle bursts showed an absence of reciprocal organisation of EMG activity. This activity was made up of either rhythmical bursts (type I and II according to the frequency) or irregular discharges (type III). Piribedil decreased tremor but facilitated EMG activity in tardive dyskinesia. These results give an objective measurement or classification of tremor and tardive dyskinesia induced by neuroleptics.

Neuroleptics have been known to produce abnormalities of movement ever since their introduction into psychiatric therapy in 1952. Tremor and choreoathetotic movements induced by neuroleptics were first described by Delay et al.' Dyskinesia secondary to long-term neuroleptic treatment was then reported by Sigwald $e t a^{2}$ and was subsequently called tardive dyskinesia. ${ }^{3}$ From a pharmacological point of view the mechanisms of these two motor disorders are different. Tremor is caused by blockade of dopaminergic receptors ${ }^{4}$ whereas the generally accepted explanation for tardive dyskinesia is that of functional overactivity of dopaminergic receptors due to hyper-sensitivity induced by "chemical denervation"..$^{5-8}$

As regards tardive dyskinesia several discrepancies exist between the animal model and clinical experience in man. For example, in rats, behavioural supersensitivity to apomorphine after discontinuation of one year of neuroleptic treatment was pres-

Address for reprint requests: Dr N Bathien, Lab. Physiologie, Fac. Med. Saint-Antoine, 27, rue Chaligny, 75571 Paris Cedex 12 , France.

Received 2 August 1983 and in revised form 19 December 1983. Accepted 4 February 1984 ent after one month, but had returned to normal after 3 months. ${ }^{9}{ }^{10}$ In man, however, tardive dyskinesia may persist long after discontinuation of neuroleptic treatment. ${ }^{11}$ Further, typical tremor $\bar{\partial}$ activity in the upper limbs has been recorded in patients with tardive dyskinesia activity localised in the face or the lower limbs. ${ }^{12}{ }^{13}$ In the light of these data we thought it appropriate to test the applicability of the supposed pharmacological mechanisms to the actual human model. In this work, EMG patterns of neuroleptic-induced tremor and tardive dyskinesia were first established. Piribedil, a dopaminergic agonist, was then injected and subsequent modifications of these patterns were used to measure the response of the dopaminergic system.

\section{Patients and methods}

Twenty-four patients were included in the study, 16 with tardive dyskinesia and eight with Parkinsonism induced by neuroleptic treatment. Details of the clinical features are given in table 1 . The neurophysiological examinations were carried out when the condition of each patient was stable. Recordings were performed with the patient in sitting position while at rest. The patient was seated in an arm-chair, the upper limb semi-flexed, the forearm supported. The leg was extended with the knee slightly flexed. Muscle activity was recorded from a pair of antagonist 
Table 1 Clinical features of patients with tardive dyskinesia and tremor induced by neuroleptics

\begin{tabular}{|c|c|c|}
\hline & $\begin{array}{l}\text { Tardive } \\
\text { dyskinesia }\end{array}$ & Tremor \\
\hline $\begin{array}{l}\text { Number of patients } \\
\text { Age: - mean } \\
\text { - range } \\
\text { Sex Duration of disease: - mean } \\
\text { - range }\end{array}$ & $\begin{array}{l}16 \\
60 \text { years } \\
\text { (47-74 years) } \\
6 \text { F } 10 \mathrm{M} \\
5 \text { years } \\
\text { (1-11 years) }\end{array}$ & $\begin{array}{l}8 \\
59 \cdot 1 \text { years } \\
\text { (43-71 years) } \\
5 \mathrm{~F} 3 \mathrm{M} \\
18.4 \text { days } \\
\text { (12-27 days) }\end{array}$ \\
\hline
\end{tabular}

muscles implicated in abnormal involuntary movements, such as the masseter (mass) and the digastric (dig) for orofacial dyskinesia, the sternocleidomastoid ( $\mathrm{scm}$ ) and the contralateral splenius (splc) for dyskinesia of the head, the flexor digitorum (fld) and the extensor digitorum (ed), the tibialis anterior (ta) and the soleus (sol) for dyskinesia of the extremities. EMG signals were picked up by Beckman disc electrodes placed over the belly of the muscle. All signals were continuously displayed by an oscilloscope and traced on paper through an Alvar 8-channel polygraph. Selected sequences were stored on magnetic tape for subsequent photographic and computer analysis.

Quantitative analysis of EMG records

EMG records taken simultaneously from the pairs of ankle antagonists, tibialis and soleus, were used to characterise the different types of abnormal involuntary movements and to analyse intrajoint coordination. The results presented are from analysis of involuntary activity occurring spontaneously during the resting state. Continuous recordings including 90 or more periods of tibialis activity were used. A period was defined as the interval between the onset of two successive tibialis bursts.

The EMG data were amplified, filtered (bandwidth $10 \mathrm{~Hz}-1 \mathrm{Khz}$ ) and full-wave rectified. They were then digitised (sampling rate: $1000 \mathrm{~Hz}$ ) by a PDP 11-03 digital computer. Block averaging the data in $5 \mathrm{~ms}$-bins resulted in digital integration of the EMG. The onset of an EMG burst was defined as the beginning of the first bin within a period of EMG activity with 20 ms duration or more. The termination of a burst was defined as the end of an EMG activity period which was followed by a pause of a $20 \mathrm{~ms}$ or more. Histograms of duration and frequency of EMG burst were performed.

The activity of the ankle antagonists (tibialis anterior and soleus muscles) was also examined in terms of phase relationships. The phase of the soleus with respect to the tibialis is defined as the latency $(\mathrm{L})$ of soleus with respect to tibialis (or the time from the onset of the tibialis burst to the onset of the subsequent soleus burst) divided by the period $(T)$ of tibialis. That is: Phase soleus, tibialis $=\mathrm{L}$ soleus, tibialis/T tibialis (fig 3). According to this definition, a phase equal to zero or one means that two muscles begin their activity at the same time. Other phase values indicate that the muscles are activated at different times. The phase values were grouped into 10 bins of $0 \cdot 1$ phase unit each and histograms were plotted to show the distribution of phase values. Pearson product-moment correlation coefficients $(r)$ were calculated for phase soleus, tibialis vs concurrent tibialis period.
In each recording session, histograms of EMG burst characteristics (duration, frequency and phase) from ankle muscles were first documented in patients with the lower limbs in resting position. Three consecutive $20 \mathrm{~s}$ epochs were analysed. Subsequently, pharmacologcal test was performed. Piribedil ( $3 \mathrm{mg}$ ) was given iv to all patients. Tremor and tardive dyskinesia were assessed by the amplitude of EMG activity (integrated EMG) and number of bursts per minute.

\section{Results}

\section{I-Electromyographic description of abnormal} involuntary movements induced by neuroleptics EMG activity of the agonist muscle and its reciprocal coordination with that of the antagonist of the same limb segment were used to define the different types of abnormal involuntary movements induced by neuroleptics. The results of the analysis of abnormal involuntary movements of the ankle are shown in figs 1,2 and 3 and table 2 . The results were also found in the face, the neck and the upper limbs, all of which were explored by recording pairs of antagonist muscles such as the masseter and digastric, the sternocleidomastoid and splenius and the extensor and flexor of the wrist.
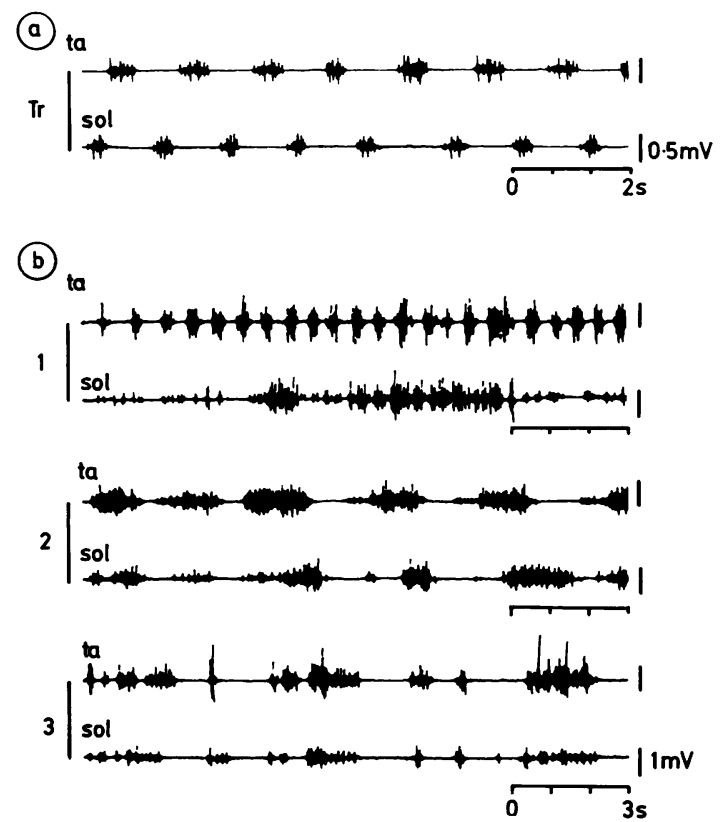

Fig 1 Patterns of EMG activity recorded from tibialis anterior (ta) and soleus (sol) muscles during abnormal involuntary movements (AIM) induced by neuroleptics. (a) tremor activity (Tr), (b) tardive dyskinesias (TD). EMG records from the ta muscle show three typical patterns during TD. Note that alternation of antagonist activity recorded during $T r$ is lacking in $T D$. 

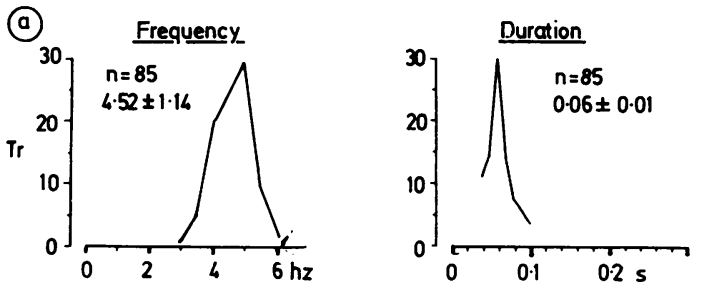

(b)
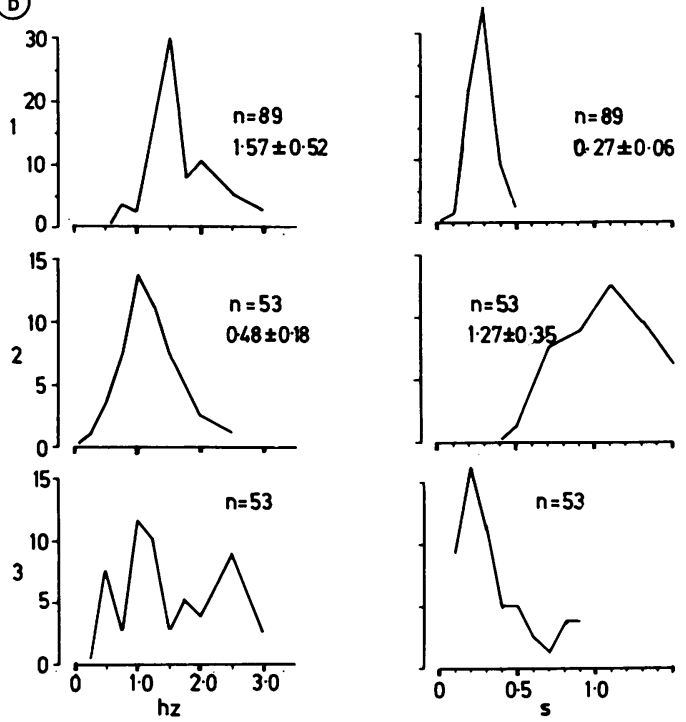

Fig 2 Histograms of frequency and duration of tibialis EMG bursts from samples in fig 1. Values are means $\pm 2 S E$ and $N=$ total number of events. These histograms show differences in the temporal characteristics of EMG bursts recorded during tremor (Tr) and tardive dyskinesias (b).

Figure 1 shows recordings of four separate types of EMG activity identified after exploration of 24 patients. Histograms representing frequency and length of firing bursts as shown in fig 2 . In tardive dyskinesia, two types of rhythmical EMG activity (groups of bursts) were found (fig 1b). Their frequency and duration were different from those recorded during tremor, where the bursts had greater mean frequency and shorter duration. In the example of fig 1, EMG bursts of the tibialis anterior (ta) recorded during tremor had a mean frequency of $4.52 \pm 1.14 \mathrm{~Hz}$ and a mean length of $0.06 \pm$ $0.01 \mathrm{~s}$

EMG activity during dyskinesia was classified into three types, two of which (types I and II) were rhythmical. Type I was clonic. Mean frequency of bursts ranged from 1 to $3 \mathrm{~Hz}$. Type II bursts were more tonic, often over 1 second in length, and with a slower frequency, always well under $1 \mathrm{~Hz}$. In fig 1 , for example, mean frequency was $0 \cdot 48 \pm 0 \cdot 18 \mathrm{~Hz}$. Type III bursts showed great variability in time characteristics. The EMG activity consisted of bursts with varying lengths, frequencies and amplitudes. Histograms of length and frequency were significantly different from normal values (fig $2 b$ ).

Analysis of phase relationships between bursts of EMG activity of agonist-antagonist muscles (tibialis and soleus) are presented as soleus/tibialis phase histograms in fig 3. Alternating tibialis and soleus muscle activity in tremor produced a peak in phase values around $0 \cdot 5$. Soleus activity clearly occurred in the intermediate phases of the tibialis burst cycle. The varying dispersion in histograms of soleus/ tibialis phases accounts for the phase shift described in Parkinsonian tremor. ${ }^{14}$ is In both types of tardive dyskinesia considered, phase histograms showed a peak near phase 0.0 with respect to tibialis bursts. This is the pattern of two antagonist muscles which are coactive. This phenomenon was observed in type I and type II tardive dyskinesia (fig 3 TDa) and also in type III (fig $3 \mathrm{TDb}$ ). In the latter case, there are several peaks including a prominent peak near $0 \cdot 0$, indicating also a tendency towards coactivation of the two antagonist muscles. Table 2 shows that $\bigcirc$ soleus/tibialis phase is not significantly correlated $\unrhd$ with concurrent tibialis period in tardive dyskinesia. The absence of reciprocal coordination of activity from antagonist muscles thus seems to be characteristic of tardive dyskinesia and therefore sets it apart from tremor.

Table 3 shows topographical distribution of abnormal involuntary movements as defined by EMG criteria. Tremor type activity with rhythmical, alternating agonist-antagonist bursts, was picked up in three out of eight patients in the orofacial area. In one patient orofacial tremor alone was present; in the other two, it was associated with tremor of the extremities. Bursts of discharges were recorded from the orbicularis oris, masseter and digastric muscles at a rate of 5-6 Hz. Mean frequency of tremor activity in the extremities and face in eight patients was $5.7 \mathrm{~Hz}$ with a $95 \%$ confidence interval of 0.4 .

In tardive dyskinesia, no predominant topographical pattern was found (table 3). In the face and extremities, the proportion of rhythmical (type I and II) bursts and type III EMG pattern were comparable. In the trunk (latissimus dorsi and teres major), type II was observed twice and type III once out of three cases. Further, in four cases tremor type activity was recorded in one extremity while tardive dyskinesia activity was taking place in another extremity or in the face. 


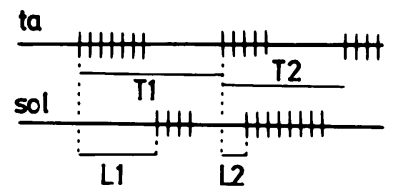

Phase $\mathrm{sol} / \mathrm{ta}=\mathrm{LI}: \mathrm{T} 1 ; \mathrm{L} 2: \mathrm{T} 2 \ldots . .$.

$\operatorname{Tr}$

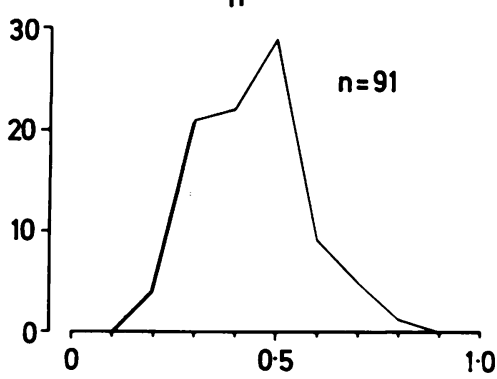

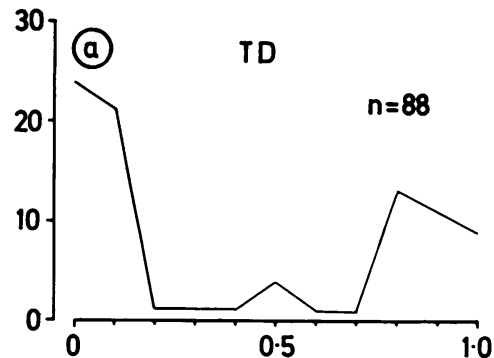

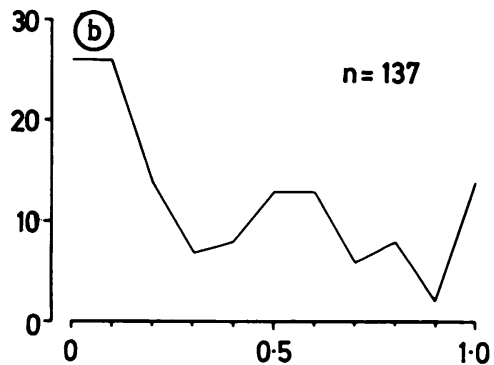

Fig 3 Histograms of the phase relationships of soleus (sol) activity with respect to tibialis (ta) activity (phase ta/sol) during tremor (Tr) and tardive dyskinesias (TD). Top (left column): schematic illustration of the method. The phase sol/ta is defined as the latency $(L)$ of sol with respect to ta divided by the period $(T)$ of ta. Data from tremor activity (Tr), type I (a) and type III (b) of TD activity in fig 1 are shown.

Sol muscle tends to be activated at intermediate phases between 0.0 and 1.0 'during Tr. Histograms of TD activity $(a, b)$ show a predominant peak near $0 \cdot 0$.

II-Pharmacological test: effect of Piribedil

Dopaminergic mechanisms of motor control were tested by iv injection of Piribedil ( $3 \mathrm{mg}$ ). Subsequent modifications of abnormal involuntary movements were quantified. Integrated EMG and number of bursts per minute during abnormal

Table 2 Correlation of phase of soleus (sol) with concurrent tibialis (ta) period from the abnormal involuntary movement samples of fig 3

\begin{tabular}{|c|c|c|c|}
\hline $\begin{array}{l}\text { Tibialis EMG } \\
\text { activity }\end{array}$ & $N$ & $\begin{array}{l}\text { Correlation coefficient } \\
\text { for phase (sol/ta) } \\
v s \text { period (ta): }(r)\end{array}$ & $\begin{array}{l}\text { Level of } \\
\text { significance } \\
\text { (p) }\end{array}$ \\
\hline \multirow{2}{*}{$\begin{array}{l}\text { Tremor } \\
\text { Tardive dyskinesias: } \\
\text { type I activity } \\
\text { type III activity }\end{array}$} & 91 & $0 \cdot 245$ & $0.02<p<0.01$ \\
\hline & $\begin{array}{r}98 \\
126\end{array}$ & $\begin{array}{l}0.173 \\
0.169\end{array}$ & $\begin{array}{l}\text { NS } \\
\text { NS }\end{array}$ \\
\hline
\end{tabular}

involuntary movements were tallied. Figures 4 and 5 show two examples of Piribedil effects.

Piribedil suppressed neuroleptic induced tremor. Figure 4 shows that after iv injection of Piribedil, the amplitude of EMG activity and number of bursts per minute significantly decreased. From the 5 th to the 11 th minute following injection, EMG firing ceased. Return of tremor was shown by low amplitude discharge potentials grouped in episodic sequences. In three patients, the decrease in tremor caused by a $3 \mathrm{mg}$ injection was shown by a drop in integrated EMG and in number of bursts per minute. In one of these, it was observed that a higher dose of Piribedil (6 $\mathrm{mg}$ iv) caused the disappearance of tremor for 10 minutes. (The two trials were done 24 hours apart.)

Piribedil did not have the same effect on tardive dyskinesia. Figure 5 shows changes recorded from a

Table 3 Topographical distribution of abnormal involuntary movements (AIM) in relation with EMG activities from 16 patients with tardive dyskinesias and eight patients with tremor

\begin{tabular}{lllcl}
\hline & $\begin{array}{c}\text { Tremor activity } \\
(n=8 \text { patients })\end{array}$ & \multicolumn{2}{l}{ Tardive dyskinesias $(n=16$ patients) } \\
\cline { 3 - 5 } & & type I activity & type II activity & type III activity \\
\hline Location of AIM: & 3 & 1 & 4 & 3 \\
$\begin{array}{llll}\text { orofacial } \\
\text { trunk }\end{array}$ & 0 & 0 & 2 & 1 \\
limbs & 7 & 4 & 6 & 5 \\
\hline
\end{tabular}




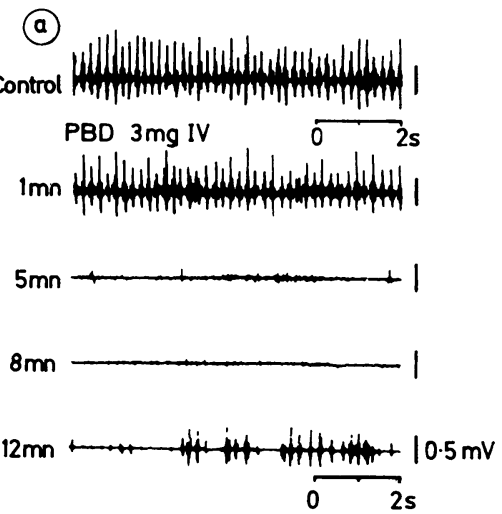

(b)

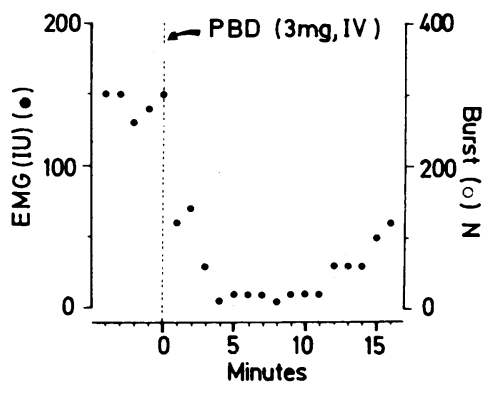

Fig 4 Effects of Piribedil (PBD) on tremor induced by neuroleptics. (a) samples of tremor activity recorded from ta muscle before and after PBD injection. (b) graph shows the effects on muscle activity quantified by integrated EMG and number of bursts during 1 minute.
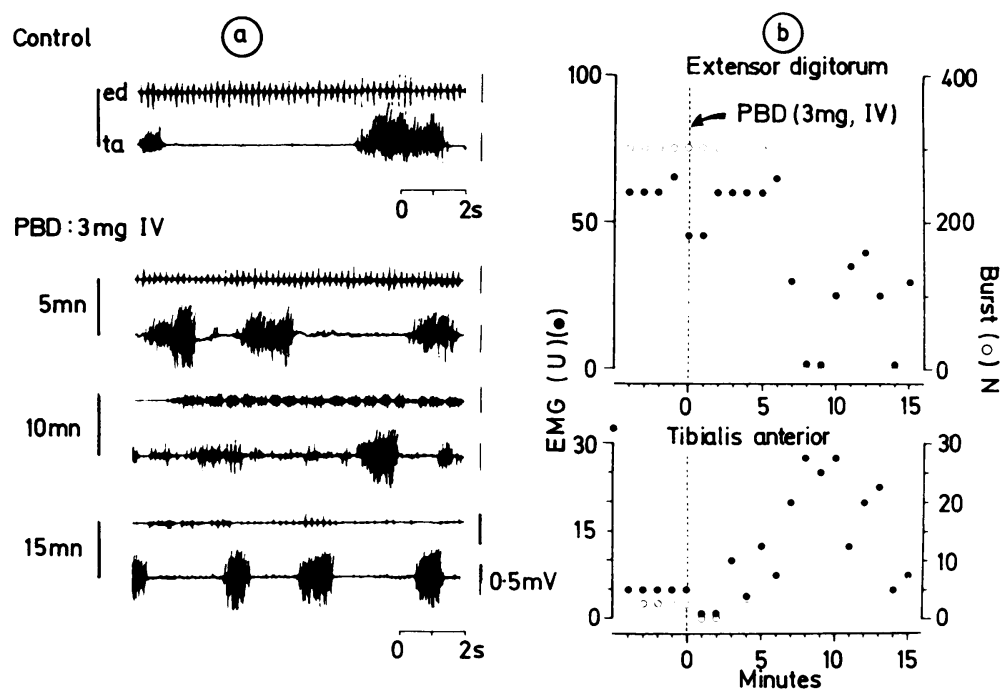

Fig 5 Effect of Piribedil on tardive dyskinesia: case of a patient with tremor activity in the upper limb and dyskinetic activity in the lower limb. (a) samples of EMG recordings from extensor digitorum (ed) and tibialis ( $t a)$ before and after Piribedil $(P B D)$ injection. (b) graphs show the effects on muscle activities quantified by integrated EMG and number of bursts during 1 minute. Note the changes in EMG patterns after $P B D$ injection.

patient with tremor in the upper extremities and type II tardive dyskinesia activity in the lower limbs. After injection the tremor type activity was replaced by longer, less frequent bursts equivalent to the type I tardive dyskinesia discharge pattern. In the lower extremity, type II bursts became more frequent. Throughout the exploration of 16 patients with tardive dyskinesia, Piribedil failed to suppress EMG activity at either the $3 \mathrm{mg}$ or $6 \mathrm{mg}$ doses. In four cases, type I tardive dyskinesia activity in the legs did not increase significantly either in amplitude or in frequency of discharges. Numbers of tonic type II bursts increased (six patients). Type III discharges tended to be grouped together in rhythmical bursts.

Side effects of iv Piribedil in these patients were rare. Some slight nausea without vomiting occurred in two cases. There was no fainting or decrease in mental alertness. 


\section{Discussion}

These results show the electrophysiological characteristics differentiating neuroleptic-induced tremor and tardive dyskinesia. They concern EMG activity during abnormal movements, existence of coordination of antagonist muscles and the effects of Piribedil, a dopaminergic agonist.

EMG recordings showed few variations in the interval and length of firing bursts in tremor (fig 2). Phase recordings of antagonist muscle activity (fig 3 ) were in favour of reciprocal organisation of bursts. These characteristics have previously been described in the resting tremor of Parkinson's disease ${ }^{16}$ Further, both are suppressed by Piribedil (fig 4). This similarity suggests that both are related to a functional underactivity of the dopaminergic system: in the former by blockade of dopaminergic receptors by neuroleptics ${ }^{4-6}$ and in the latter by deficiency in the synthesis of dopamine.

The diversity of motor side-effects during longterm neuroleptic treatment was reported in the very first publications on the subject. ${ }^{2}$ Abnormal involuntary movements induced by chlorpromazine and butyrophenone were first recorded by Rondot and Ribadeau-Dumas. ${ }^{12}$ In the present work, quantitative analysis of the patterns of EMG discharges had enabled us to characterise three types of activity. Types I and II are rhythmical and composed of bursts of varying length. Type III includes discharges which are variable in amplitude and in length and have irregular rates. No reciprocal coordination of antagonist muscle activity was observed in abnormal involuntary movements. Phase histograms showed that EMG firing tended to occur concurrently in agonist and antagonist muscles (fig 3). Also, these activities were not suppressed by Piribedil. These same properties are shared by dopa-induced dyskinesia. ${ }^{13-17}$

The hypothesis of super-sensitivity of dopaminergic receptors that have been "chemically denervated" by neuroleptics has widely been accepted as the explanation of tardive dyskinesia. 161819 However, patients with dyskinetic activities recorded in one limb may also show tremor in another. ${ }^{12}$ Piribedil has a different effect on each of these two activities. ${ }^{13}$ Figure 5 represents one of four such cases encountered in the present work. Kuo and Carpenter ${ }^{20}$ and Iansek and Porter ${ }^{21}$ reported a somatotopic organisation of movementrelated neurons in the pallidum. It is thus not inconceivable that in certain cases, the regional effects of neuroleptic on dopaminergic receptors can be different and that movement disorders can present topographically distinct clinical pictures.

Abnormal involuntary movements induced by neuroleptics in man are related to at least two different mechanisms of dopaminergic receptor functioning. Tremor is due to functional underactivity and which is corrected by Piribedil. Tardive dyskinesia is due to functional over-activity with three different types of EMG activity, all exaggerated by Piribedil.

We are grateful to $M$ Smith for improving the English text. This work is supported by a grant from INSERM PRC 1981 "Santé mentale et cerveau".

\section{References}

' Delay J, Deniker P, Green A, Mordret MY. Le syndrome excito-moteur provoqué par les médicaments neuroleptiques. Presse Méd 1957;65:1771-4.

2 Sigwald J, Banthec D, Raymondeau G, Piot G. Quatre cas de dyskinésie facio-bucco-linguo-masticatrice à évolution prolongée secondaire à un traitement par les neuroleptiques. Rev Neurol (Paris) 1959;100:751-5.

${ }^{3}$ Uhbrand L, Faurbye A. Reversible and irreversible dyskinesia after treatment with perphenazine, chlorpromazine, reserpind, ECT therapy. Psychopharmacologia 1960;1:408-18.

${ }^{4}$ Van Rossum JM. The significance of dopamine receptor blockade for the action of neuroleptic drugs. Proc. Vth Int. Congr. CINP, Washington, 1966. Excerpta Medica 1967;129:321-9.

${ }^{5}$ Klawans HL. The Pharmacology of Extrapyramidal Movement Disorders. Basel: Karger, 1973.

- Carlsson A. Mechanism of action of neuroleptic drugs. In: Lipton MA, Dimascio A, Killan KF, eds. Psychopharmacology: A Generation of Progress. New York: Raven Press, 1978:1057-70.

${ }^{7}$ Rondot P, Bathien N. Mouvements anormaux induits par les médicaments psychotropes. L'Encéphale 1979;5:41-8.

${ }^{8}$ Baldessarini RJ. The pathophysiological basis of tardive dyskinesia. TINS 1979:133-5.

${ }^{9}$ Clow AT, Jenner P, Marsden CD. Changes in dopamine mediated behaviour during one year's neuroleptic administration. Eur J Pharmacol 1979;57:365-75.

${ }^{10}$ Clow AT, Jenner P, Marsden CD. Changes in cerebral dopamine function induced by a year's administration of trifluoperazine or thioridazine and their subsequent withdrawal. In: Long Term Effects of Neuroleptics. Adv. in Biochemical Psychopharmacology, 24. Cattabeni F, Racagni G, Spano PF, Costa E, eds. New York: Raven Press, 1980:335-40.

"Crane GE. Persistent dyskinesiz. Br J Psychiatry 1973;122:395-7.

12 Rondot P, Ribadeau-Dumas JL. Dopamine et mouvements anormaux. Rev Neurol (Paris) 1972;127:99113.

${ }^{13}$ Bathien N, Rondot P, Koutlidis RM. Neurophysiologie clinique des dyskinésies tardives post-neuroleptiques et des dyskinésies dopa-induites de la maladie de Parkinson. J Physiol (Paris) 1981;77:131-44.

${ }^{14}$ Jung R. Physiologische Untersuchungen Uber den Par- 
kinsontremor und andere Zitterformen beim Menschen. Z Ges Neurol Psychiat 1941;173:263-332.

${ }^{15}$ Gybels JM. The Neural Mechanism of Parkinsonian Tremor. Bruxelles: Arscia, 1963.

${ }^{16}$ Rondot P, Bathien N. Pathophysiology of Parkinsonian tremor. In: Desmedt JE, ed. Physiological Tremor, Pathological Tremors and Clonus. Basel: Karger, 1978:138-49.

${ }^{17}$ Bathien N, Toma S, Rondot P. Comparative studies of spinal reflexes in L-dopa dyskinesia and dystonia. In: Poirier LJ, Sourkes TL, Bedard PJ, eds. Advances in Neurology, vol. 24. New York: Raven Press, 1979:353-60.

${ }^{18}$ Klawans HL, Crossett P, Dana N. Effect of chronic 